\title{
Improvement of Fatigue Properties of Resistance Spot Welded Joints in High Strength Steel Sheets by Shot Blast Processing
}

\author{
Hiroki FUJIMOTO, ${ }^{1) *}$ Hideki UEDA, ${ }^{1)}$ Rintaro UEJI2) and Hidetoshi FUJII') \\ 1) Nippon Steel \& Sumitomo Metal Corporation, 20-1 Shintomi, Futtsu, Chiba, 293-8511 Japan. \\ 2) Joining and Welding Research Institute, Osaka University, 11-1 Mihogaoka, Ibaraki, Osaka, 567-0047 Japan.
}

(Received on January 25, 2016; accepted on March 15, 2016; J-STAGE Advance published date: May 1, 2016)

\begin{abstract}
This paper discusses the effect of shot blast processing on the fatigue strength of resistance spot welded joints of $980 \mathrm{MPa}$ steel sheets and the mechanism by which the fatigue strength is improved.

The fatigue limit load of shot blasted spot welded joints was extended to approximately twice that of the non-blasted types. While high compressive residual stress was conferred on the outer surface of the shot blasted steel sheets, there was little variation in the residual stress on the side of the overlapped surface. Shot blasting on the outer sheet surface increased the initiation life of the fatigue cracks that occurred on the overlapped surface and reduced the propagating speed of the cracks that grow from the overlapped surface toward the outer surface. The initiation and propagation of fatigue cracks were affected in the region where compressive residual stress was not conferred. An FE-analysis suggests that the compressive residual stress on the outer sheet surface reduces the opening of the sheet separation of the spot welded joints under the fatigue test load and reduces the maximum principal stress around the tip of the corona bond.
\end{abstract}

KEY WORDS: resistance spot welding; high strength steel sheets; shot blasting; fatigue strength; residual stress.

\section{Introduction}

Resistance spot welding is a major welding method for assembling automobiles. Automotive bodies comprise 300 to 400 pieces of press-formed parts, which are assembled by 3000 to 5000 spot welds. To achieve lighter automotive bodies and higher safety improvement against collision, the application of high strength steel sheets in automotive bodies has increased recently. However, the fatigue strength of spot welded joints in steel sheets has been reported to be generally identical irrespective of the tensile strength of the steel sheets. ${ }^{1-3)}$ The fatigue strength of the spot welded joints deteriorates when thinner steel sheets are used. To enable the use of thinner high strength steel sheets for parts that require high fatigue resistance, the fatigue strength of spot welded joints needs to be improved.

In the case of fillet welded joints by arc welding, several methods have been proposed to improve the fatigue strength of the welded joints, including reducing the stress concentration by finishing the toe of the weld beads with a grinder, ${ }^{5)}$ using low temperature transformation welding wires to impose compressive residual stress, ${ }^{6)}$ and reducing the stress concentration by applying an ultrasonic impact treatment to the weld bead toes. ${ }^{7)}$ All of these methods directly address the weld toe of the beads where fatigue

\footnotetext{
* Corresponding author: E-mail: fujimoto.fh2.hiroki@jp.nssmc.com DOI: http://dx.doi.org/10.2355/isijinternational.ISIJINT-2016-043
}

cracks initiate.

In the case of spot welded joints, weld nuggets form on the overlapped surface of a steel sheet, and fatigue cracks initiate at the tip of the notch in the corona bond portion lying around the nugget in the overlapped surface of the steel sheet. They then propagate toward the outer surface of the steel sheet. In the spot welding, therefore, it is difficult to modify the stress concentration, or control the chemical composition of the weld metal using welding materials. Methods by which either post heat treatment after spot welding $^{8)}$ or that by cold forging on the welded joints after the spot welding have been reported to improve the fatigue strength of the spot welded joints. ${ }^{9)}$ However, a simpler method is required for application to manufacturing.

Shot blasting is used to improve the fatigue strength of machine components such as gears or shafts. Recently, we have arranged shot blasting to develop a new method that can improve the fatigue strength of spot welded joints even without directly processing the initiation points of the fatigue cracks. In the field of automotive body parts production, shot blasting is used to produce press-hardened parts using uncoated hot-stamped steel sheets. ${ }^{10)}$ For producing press-hardened parts, shot blasting is applied to eliminate iron scales formed on the steel sheet surface during the heating process of hot-stamped steel sheets. For our method, shot blasting is applied to enhance the fatigue properties of the spot welded joints. This method could contribute to the improvement of the fatigue properties of the spot welded 
joints especially for the chassis parts of automobiles such as the front sub-frames, rear sub-frames, and lower arms where high fatigue properties are required.

This study demonstrates that the fatigue life of spot welded joints can be improved by shot blast processing using high strength steel sheets with a $980 \mathrm{MPa}$ grade tensile strength. In addition, it considers the improvement mechanism of the fatigue properties in the case where the fatigue cracks initiate and propagate from an overlapped surface.

\section{Experimental Method}

The chemical composition and the mechanical properties of the steel sheets used in this study are listed in Table 1. Cold rolled steel sheets with a tensile grade strength of 980 $\mathrm{MPa}$ and a thickness of $1.2 \mathrm{~mm}$ were used. The shape and dimensions of the fatigue specimens are shown in Fig. 1. The welding conditions of the spot welds are listed in Table 2. The welding conditions were modified to obtain a nugget diameter of $4.7 \mathrm{~mm}$. This value is equal to $4.25 \sqrt{\mathrm{t}}$ ( $\mathrm{t}$ : thick-

Table 1. Chemical composition and mechanical properties of the steel sheets.

\begin{tabular}{cccccc}
\hline Grade & $\mathrm{C}$ & $\mathrm{Si}$ & $\mathrm{Mn}$ & $\mathrm{P}$ & $\mathrm{S}$ \\
\hline $980 \mathrm{MPa}$ & 0.15 & 0.13 & 2.58 & 0.008 & 0.002 \\
\hline & & & mass\% \\
\hline $\begin{array}{c}\text { Thickness } \\
(\mathrm{mm})\end{array}$ & $\begin{array}{c}\text { Yeild strength } \\
(\mathrm{MPa})\end{array}$ & $\begin{array}{c}\text { Tensile strength } \\
(\mathrm{MPa})\end{array}$ & Elongation (\%) \\
\hline 1.2 & 702 & 1087 & 15 \\
\hline
\end{tabular}

Table 2. Welding conditions.

\begin{tabular}{cc}
\hline Welder & AC stationary \\
Electrode & DR type, Tip face: $\phi 6 \mathrm{R} 40$ \\
Force & $3.4 \mathrm{kN}$ \\
Welding time & $267 \mathrm{msec}(16 \mathrm{cycles} / 60 \mathrm{~Hz})$ \\
Welding current & $5.7 \mathrm{kA}$ \\
Holding time & $167 \mathrm{msec}(10 \mathrm{cycles} / 60 \mathrm{~Hz})$ \\
\hline
\end{tabular}

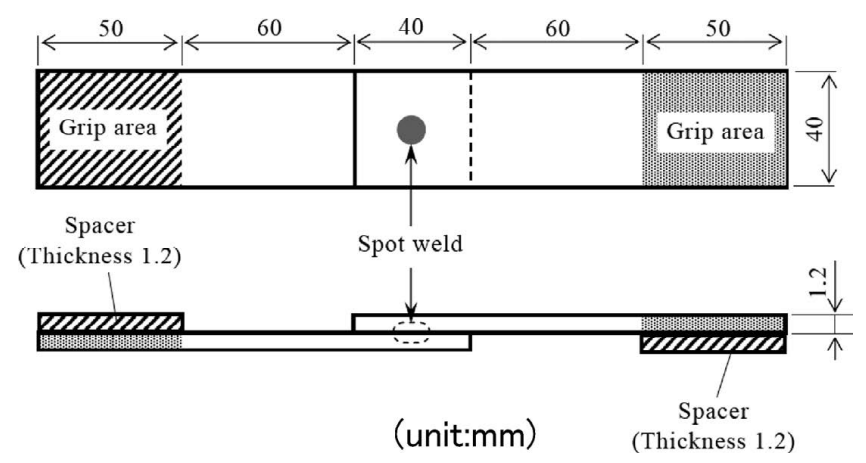

Fig. 1. Shape and dimensions of the fatigue test specimen. ness). Figure 2 shows how the shot blasting was processed. The shot blasting was performed using a pneumatic shot blasting machine, BA-1, made by Atsuchi Tekko Co., Ltd., by blasting steel beads of $0.3 \mathrm{~mm}$ diameter on both sides of the spot welded specimens at an air pressure of $0.35 \mathrm{MPa}$, and a blasting distance of approximately $150 \mathrm{~mm}$. The shot blasted spot welded specimens and non-shot blasted ones were prepared and their fatigue strengths were evaluated in accordance with JIS Z3138 (Fatigue Testing Method of Spot Welded Joints). A fatigue testing machine, EHF-EV20 kN, with a capacity of $20 \mathrm{kN}$ made by Shimadzu Corporation, was used. Testing was conducted under load control at a load ratio, $\mathrm{R}=0.1$. When the displacement of the fatigue specimens reached a value of $1 \mathrm{~mm}$ or higher than the initial displacement, the specimen was identified as a failure and the number of cycles to failure was recorded.

As the fatigue cracks of the spot welded joints propagate from the overlapped surface of the steel sheets toward the outer surface, the fatigue tests were interrupted at a designated number of cycles, and the behavior of the initiation and propagation of the fatigue cracks were examined through observing the cross section in the nugget center of the specimens in the parallel direction to the tensile load. For the fatigue testing at that time, a load range of $1.75 \mathrm{kN}$ was adopted.

In addition, the residual stress distribution around the spot welded joints, which was assumed to affect the fatigue properties, was measured. To specify the correlation between the fatigue properties and residual stress, it is necessary to measure the residual stress on the overlapped portions of the steel sheets at which the fatigue cracks initiate. To measure the residual stress of the overlapped surface, this study adopted the method shown in Fig. 3. The test specimen comprises three parts for the measurement of residual stress. One is that with a previously opened hole, and another is small steel sheet for stuffing the hole. Before spot welding was performed, the steel sheet, of which the hole was stuffed with a small steel sheet, was overlapped on the steel sheet for measuring the residual stress. For

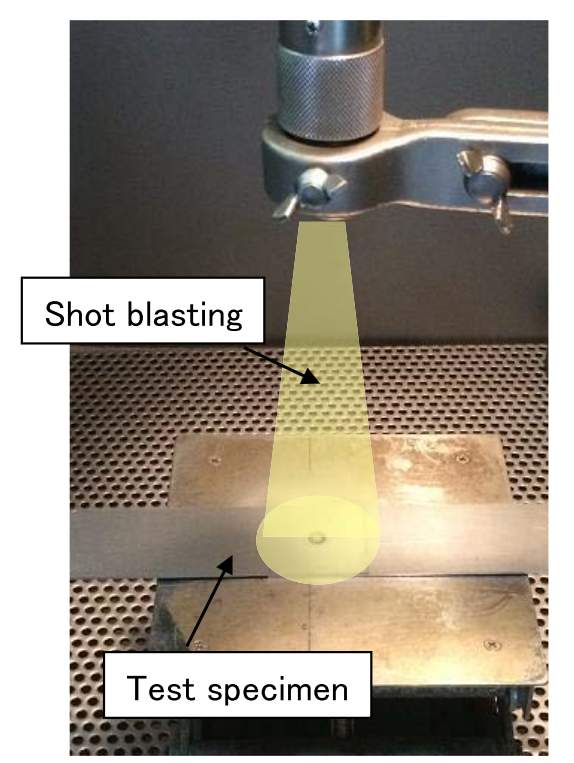

Fig. 2. Shot blasting method. (Online version in color.) 


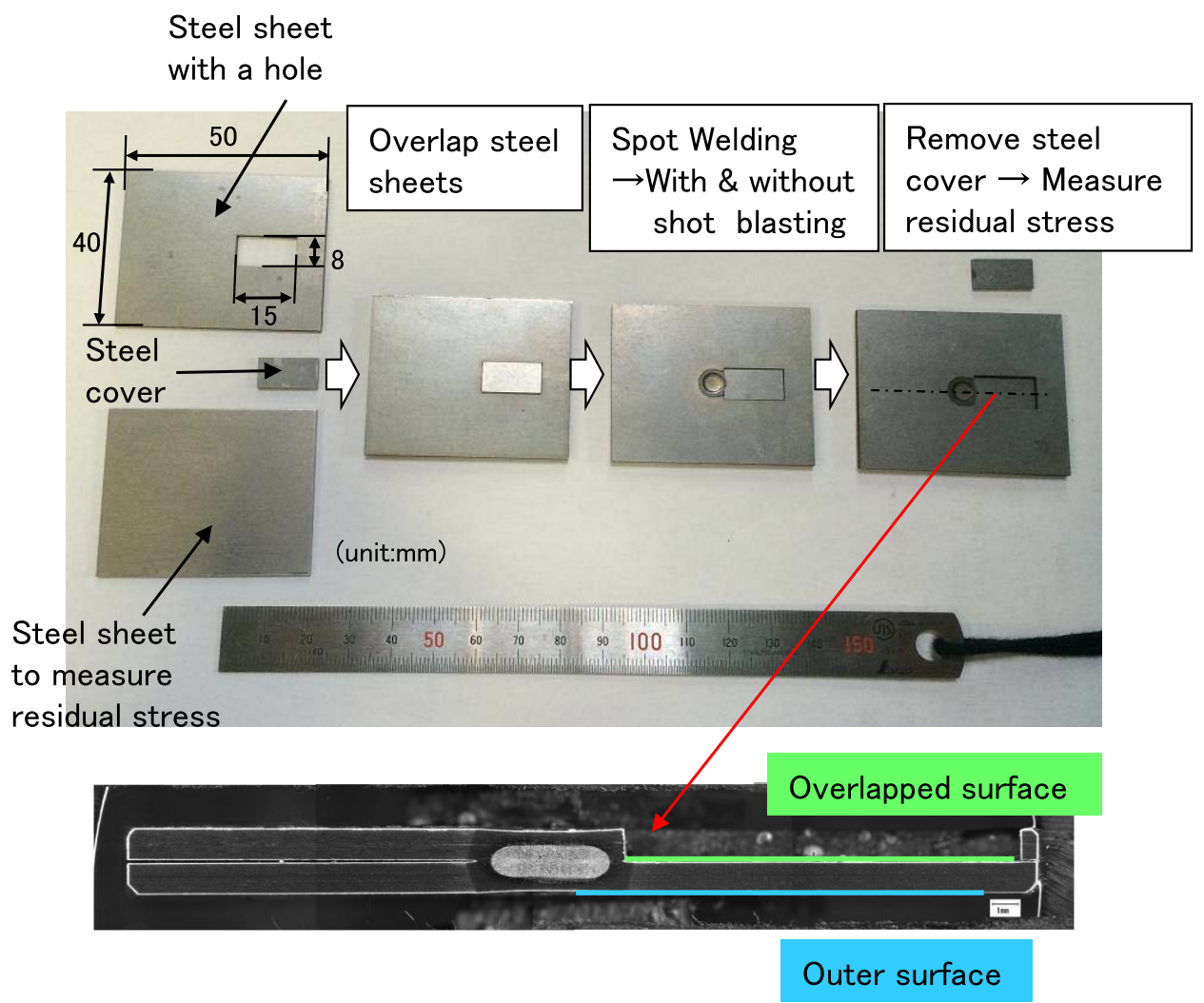

Fig. 3. Procedure for preparation of specimen for the measurement of residual stress by X-ray. (Online version in color.)

specimens without shot blasting, the residual stress on the overlapped surface and outer surface of the steel sheets was measured after removing the steel sheet used to stuff the hole. In addition, for the specimens with shot blasting, the steel sheet used to stuff the hole was removed after the shot blast processing, then the residual stress was measured. The X-ray diffractometer, PSPC-RSF model produced by Rigaku Corporation was used to measure the residual stress. The residual stress in the radial direction to the nuggets, which was assumed to affect the fatigue, was measured. The measurement region was $0.5 \mathrm{~mm}$ in diameter and the measurement ranged from the nugget center to $10.0 \mathrm{~mm}$ in the outer surface of the steel sheets. As it is impossible to measure the residual stress inside the nuggets on the overlapped surface, the measurement was conducted in a range from $3.0 \mathrm{~mm}$ to $8.0 \mathrm{~mm}$ from the nugget center. In addition, to investigate the residual stress along the depth direction of the steel sheets due to shot blasting, the residual stress along the depth direction was investigated by polishing the surface with electrolyte polishing at a position $10 \mathrm{~mm}$ away from the nugget center.

The static implicit method according to the universal FEM analysis code of Abaqus ver.6.12 was employed to calculate the stress distribution in spot welded joints.

\section{Results and Discussion}

\subsection{Effects of Shot Blasting on the Fatigue Properties of the Spot Welded Joints}

The appearances of the spot welded specimens with and without shot blasting are shown in Fig. 4(a). The shot blasted ones show little difference compared to the non-shot-blasted ones, while the surface of the spot welds shows a slightly lighter colored oxidized portion. Figure 4(b) shows the steel sheet surfaces observed by SEM. The shot blasted ones have a slightly larger uneven surface compared to the non-shot blasted ones. The hardness distribution of the spot welded joints with and without shot blasting are shown in Fig. 5. No significant variation in the hardness distribution measured $0.2 \mathrm{~mm}$ away from the overlapped surface along the parallel direction to the thickness was observed. In the case where the hardness was measured along the thickness direction, in the joints with shot blasting, slightly higher hardness of HV337 was identified to a depth of approximately $0.1 \mathrm{~mm}$ from the outer surface. When the measurement location reached $0.2 \mathrm{~mm}$ in depth, the hardness had the same value as in those without shot blasting.

The fatigue test results of the spot welded joints with and without shot blasting are shown in Fig. 6. The shot blasted spot welded joints had longer life cycles to failure and the fatigue limit load was approximately twice that of the non-shot blasted ones. This result clearly indicates that the fatigue properties of the spot welds were improved by the shot blast processing. Figure 7 shows the failure mode in the fatigue test. Fatigue cracks growing from the tip of a notch of the corona bond portion around a nugget were observed in the shot blasted ones and non-shot blasted ones; however, no explicit difference was identified in the position of the fatigue cracks between the two joints.

\subsection{Effects of Shot Blasting on the Residual Stress of the Spot Welded Joints}

Figure 8(a) shows the residual stress distribution on the outer surface of the spot welded joints. The residual stress 


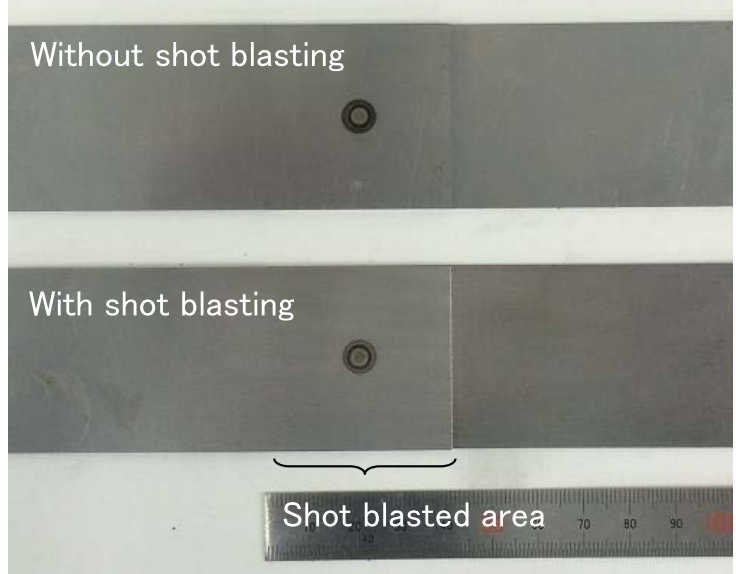

(a) Appearance of test specimen
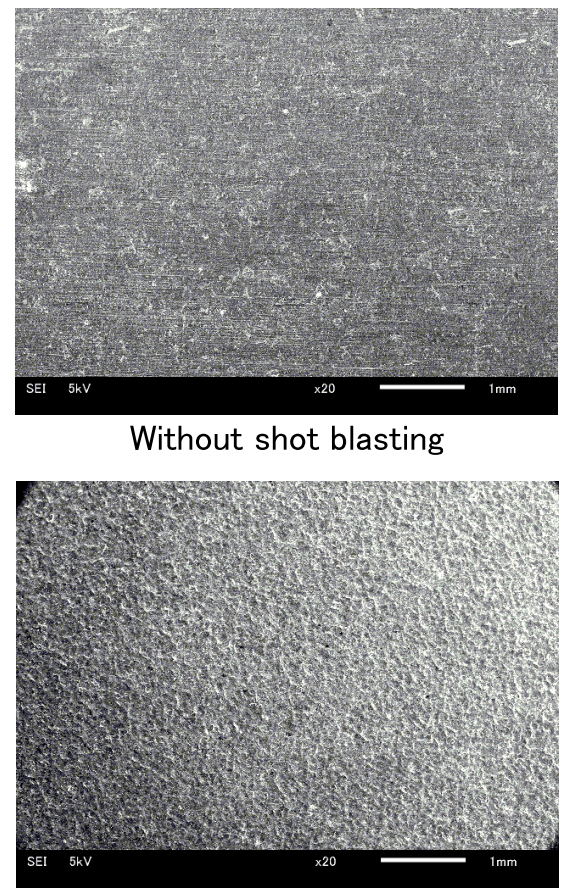

With shot blasting

(b) SEM observation of steel surface

Fig. 4. Comparison of test specimen with and without shot blasting. (Online version in color.)

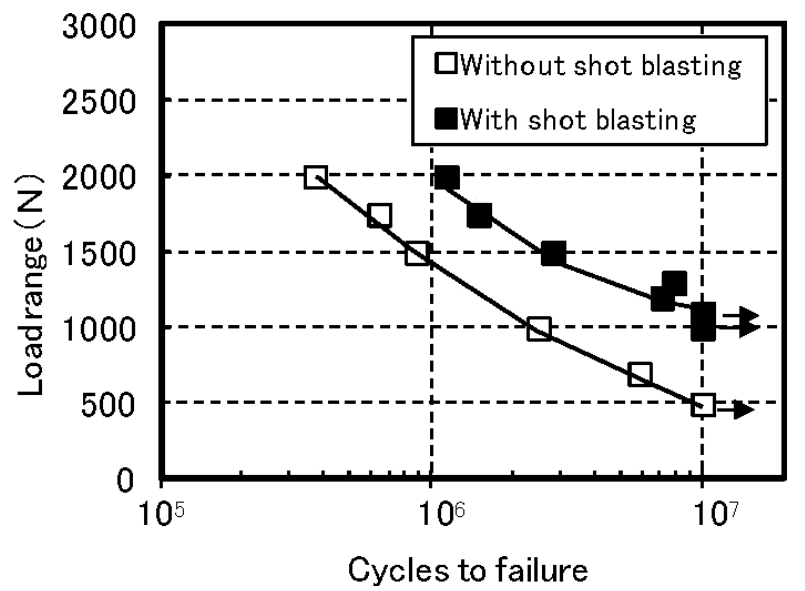

Fig. 6. Fatigue test results of spot welds with and without shot blasting.
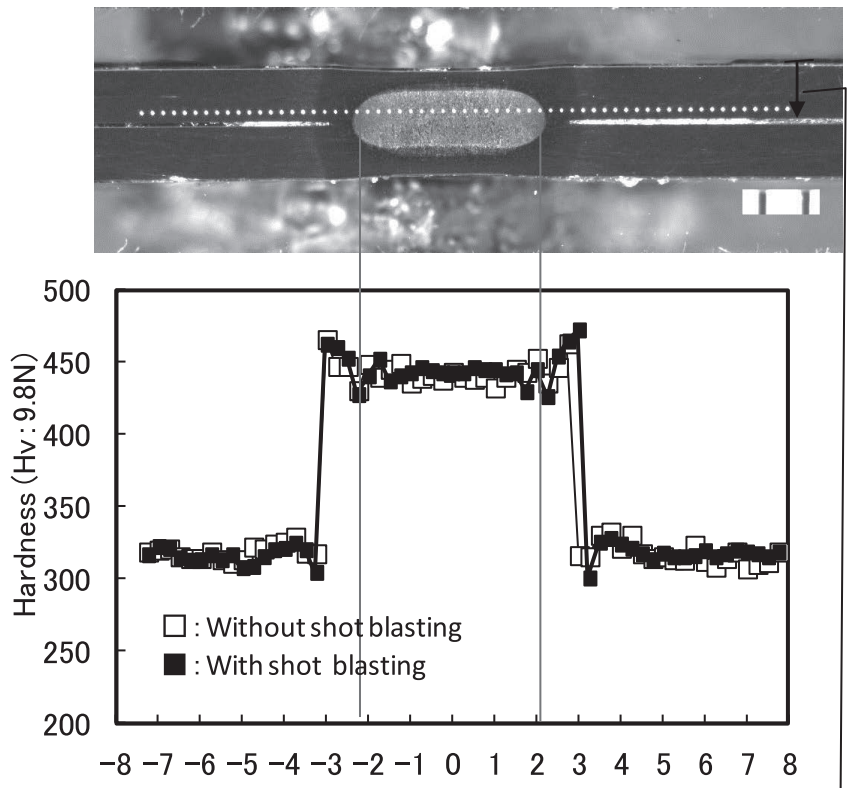

Distance from center of nugget $(\mathrm{mm})$

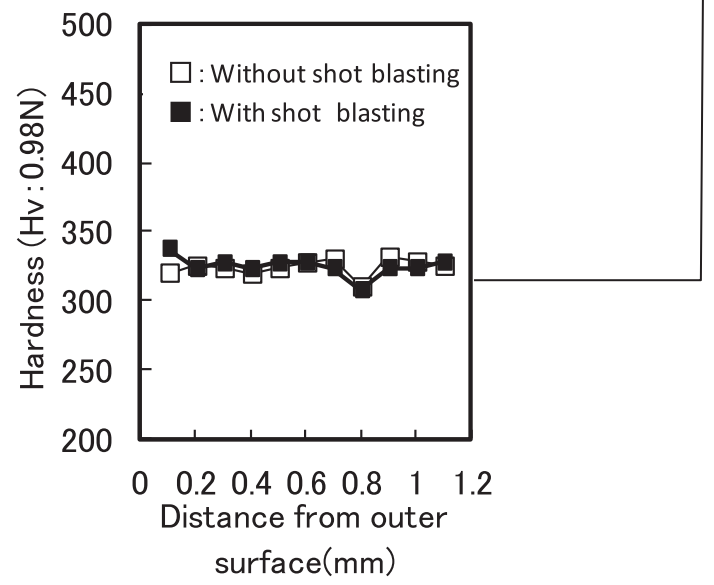

Fig. 5. Hardness profile of $980 \mathrm{MPa}$ steel spot welds with and without shot blasting.

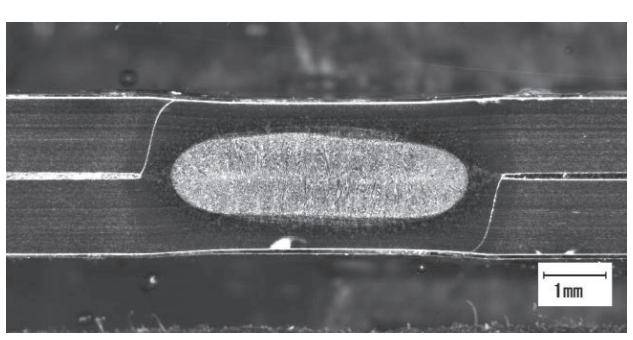

(a) Without shot blasting

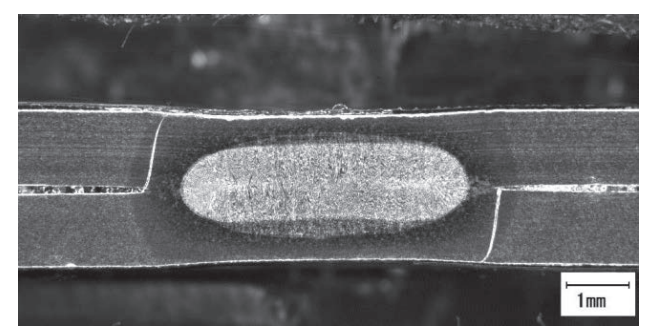

(b) With shot blasting

Fig. 7. Failure mode of $980 \mathrm{MPa}$ steel spot welds in fatigue tests (Load range: $1.75 \mathrm{kN}$ ). 
in the spot welded joints without shot blasting is high tensile stress at the nugget center, and that decreased with the distance from the center. The tensile stress condition was observed approximately $3 \mathrm{~mm}$ away from the nugget center, and this length well coincides with the length where the fatigue cracks propagated. In the spot welded joints with shot blasting, a compressive residual stress of around $500 \mathrm{MPa}$ was identified at all the measurement points. The residual stress distributions on the overlapped surface are shown in Fig. 8(b). The shot blasting did not significantly affect the residual stress on the overlapped surface. Both the joints mainly showed tensile residual stress and their orders were similar to each other at a position approximately 3 mm away from the nugget center. It should be noted that this portion is in the vicinity of the initiation portion of the fatigue cracks.

Figure 9 shows the residual stress along the radius direction that was measured in the depth direction from the outer surface of the steel sheets $10 \mathrm{~mm}$ away from the nugget center. A tensile residual stress of approximately $50 \mathrm{MPa}$ was identified in the joints without shot blasting. Meanwhile, in the joints with shot blasting, a compressive residual stress of approximately $500 \mathrm{MPa}$ was identified to a depth of approximately $0.1 \mathrm{~mm}$ from the surface, and the magnitude of the compressive stress decreased as the depth increased.
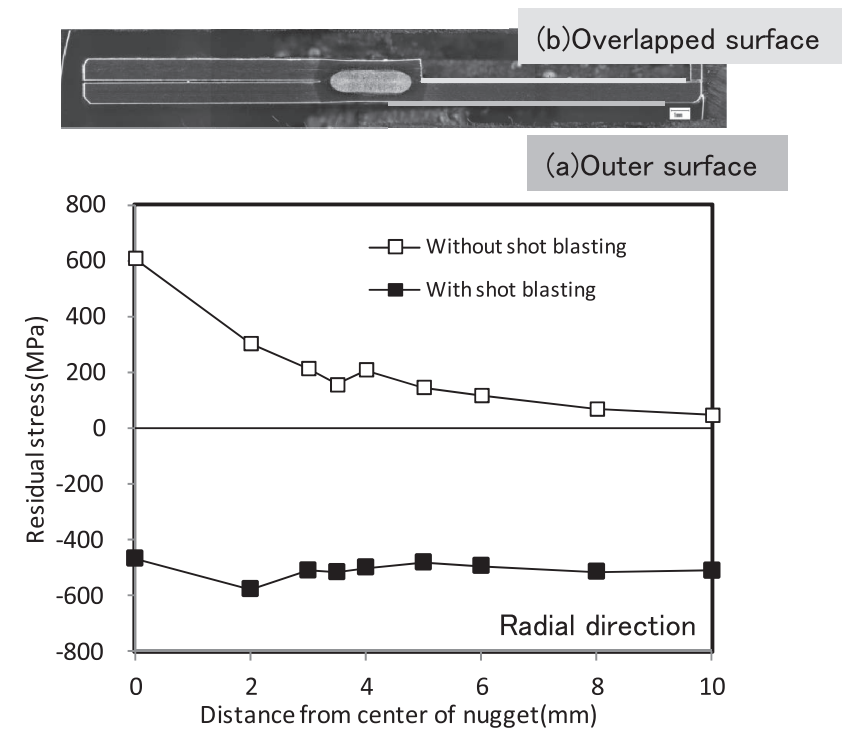

(a) Outer surface

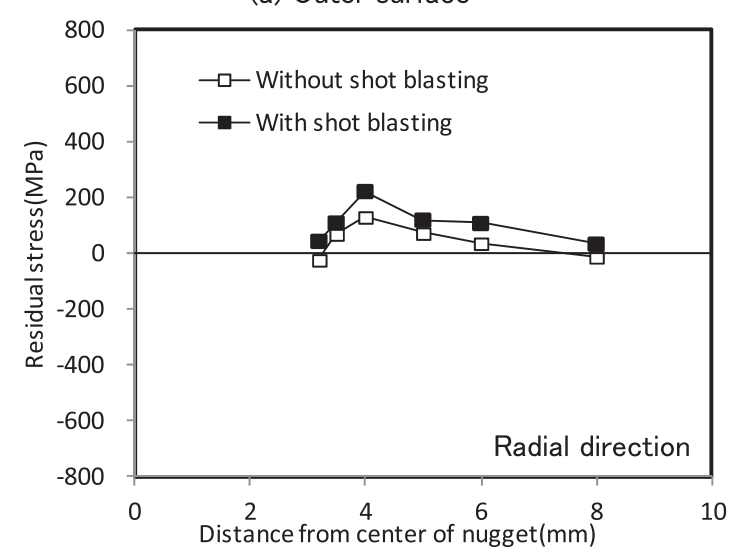

(b) Overlapped surface

Fig. 8. Residual stress distributions around the spot welds.
When the measurement location reached $0.25 \mathrm{~mm}$ in depth, the residual stress had the same value as in those without shot blasting.

These indicate that, while a large compressive residual stress can be introduced on the outer surface of the steel sheets by the shot blasting, the residual stress of the overlapped surface, which was the initiation point of the fatigue cracks, was not impacted by the shot blasting and remained at the same level as those without shot blasting. It is generally considered that tensile residual stress that balances the compressive residual stress by shot blasting may be generated. However, this phenomena was not clearly observed. This might be caused by slight deformation of specimen that results in the relief of tensile residual stress.

\subsection{Effects of Shot Blasting the Outer Surface of the Steel Sheets on the Initiation/Propagation Behav- ior of Fatigue Cracks from the Overlapped Sur- face}

To clarify the effect of shot blasting on the initiation/ propagation behavior of the fatigue cracks, the lengths of the fatigue cracks during the fatigue tests were measured. Figure 10(a) shows cross sections of the specimen loaded in $4 \times 10^{4}$ cycles. Small fatigue cracks were identified in the plate thickness direction from the notch tip of the corona bond in the joints without shot blasting, and, in contrast, no fatigue cracks were identified in the shot-blasted joints. Figure 10 (b) shows the cross sections after $1 \times 10^{5}$ cycles. While all of the joints had fatigue cracks propagating in the plate thickness direction from the notch tip of the corona bond, the joints without shot blasting exhibited longer fatigue cracks than those of the shot-blasted joints.

The lengths of the fatigue cracks are shown in Fig. 11. Since fatigue cracks were observed in the two right and left positions of the nugget, the lengths of both were plotted. Figure 11 reveals that the initiation of fatigue cracks was delayed in the joints with shot blasting compared to those without shot blasting. The initiation life of the fatigue cracks seems to be around $1.5 \times 10^{4}$ cycles in the joints without shot blasting and around $8 \times 10^{4}$ cycles in those with shot blasting. In addition, this graph of logarithmic representation along the horizontal direction indicates that the joints with shot blasting had slower rates of crack propagation, as plotted on the right side, than those without shot blasting.

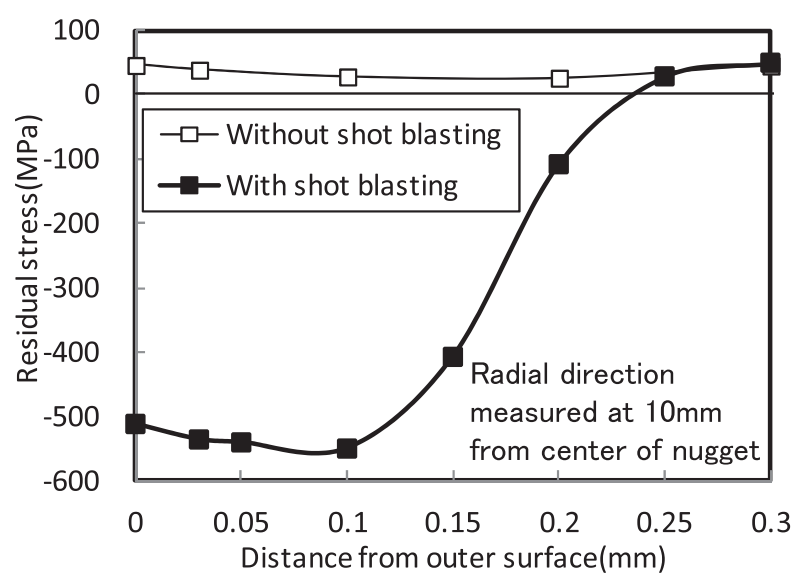

Fig. 9. Residual stress distributions in the thickness direction. 


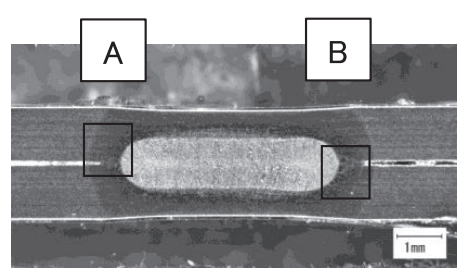

Without shot blasting

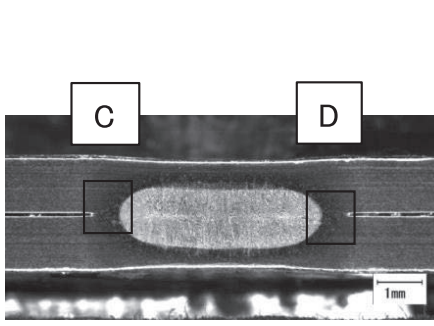

With shot blasting
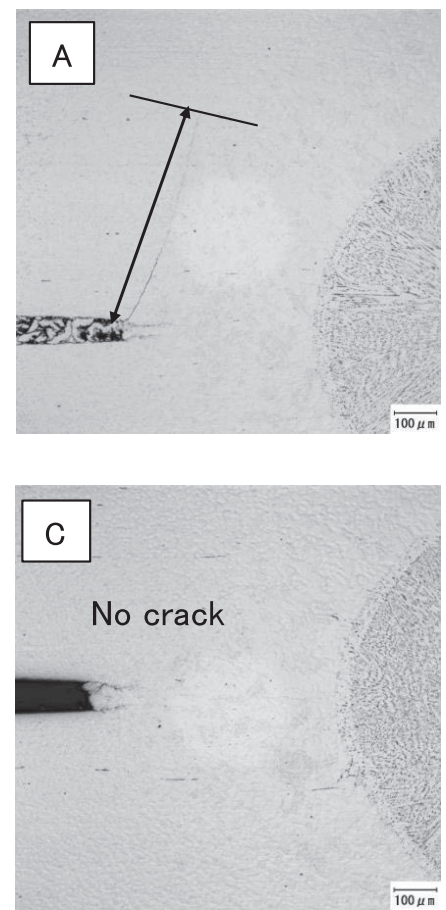

(a) $4.0 \times 10^{4}$ cycles
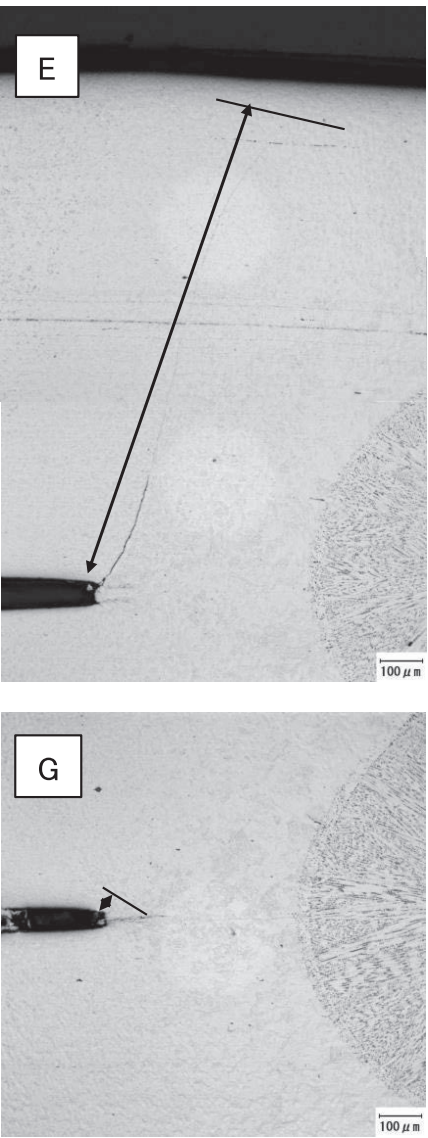

(b) $1.0 \times 10^{5}$ cycles
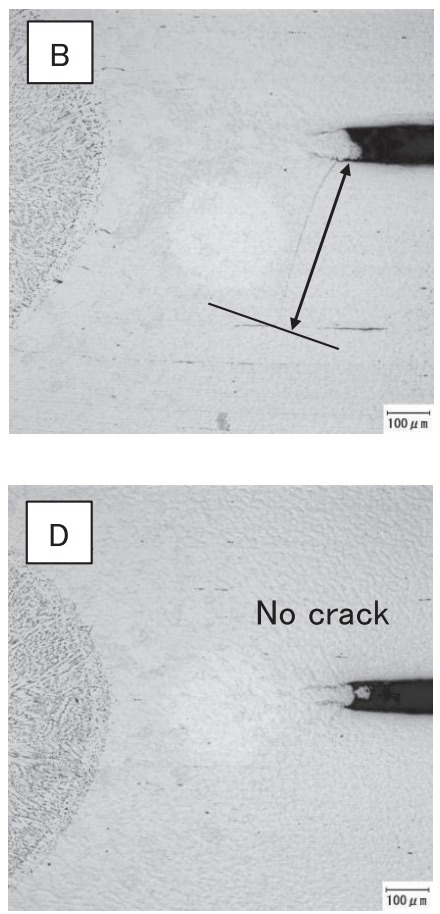

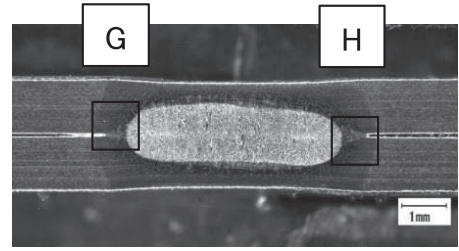

With shot blasting

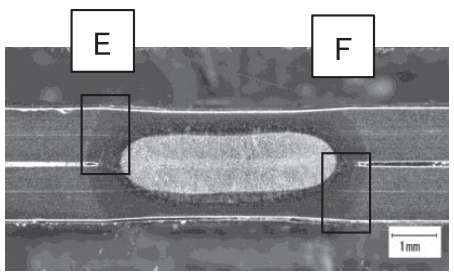

Without shot blasting

(b) 1.0X10 cycles

Fig. 10. Comparison of the fatigue crack behavior of spot welds with and without shot blasting (Load range: $1.75 \mathrm{kN})$.

Interestingly, both the crack initiation and propagation are delayed in the region where the compressive residual stress is not conferred.

\subsection{Effects of Shot Blasting on Stress Distribution and Deformation in the Fatigue Tests}

To clarify the mechanism of the improved fatigue life by shot blasting on the outer surface, the stress in the joints was evaluated by applying the finite element method analy- 
sis (FEM analysis) that simulates the load condition in the fatigue test of the spot welded joints with and without shot blasting. The analysis model is shown in Fig. 12. Modeling was conducted in the form of half symmetry in the plate width direction, such that the nugget diameter and corona bond diameter were defined as $4.7 \mathrm{~mm}$ and $5.9 \mathrm{~mm}$, respectively, based on the measurement results of the cross section of the welded joints used in the test, and mesh division was performed with hexahedral elements of reduced integration. The residual stress due to shot blasting was established in the region of $0.15 \mathrm{~mm}$ from the superficial layer of the outer steel sheets based on Fig. 9.

Figure 13 shows the analysis model. Case 1 and Case

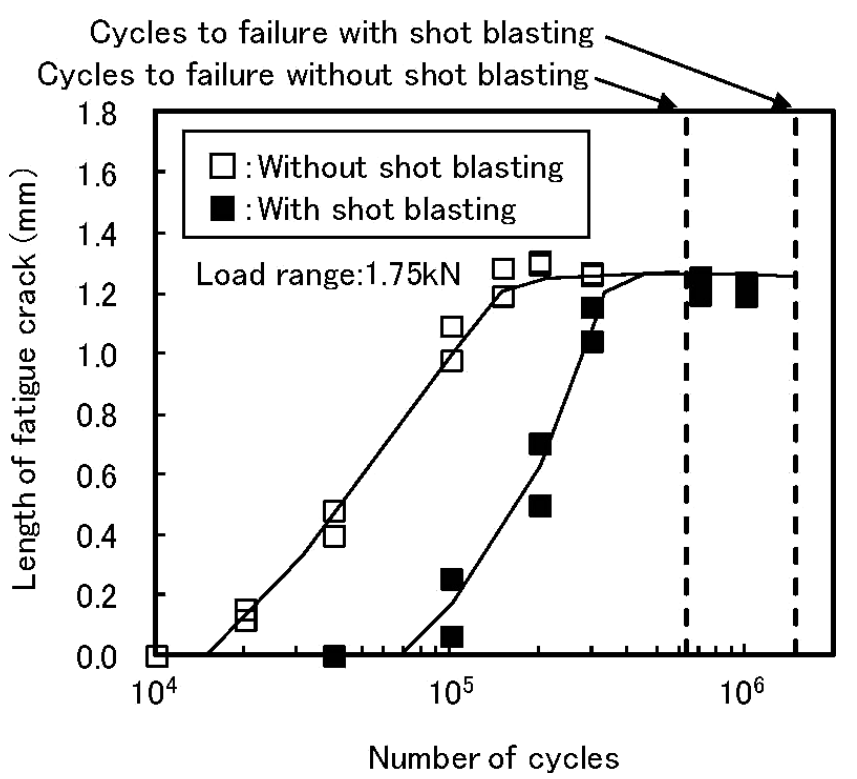

Fig. 11. Effect of shot blasting on the fatigue crack length of the spot welds.

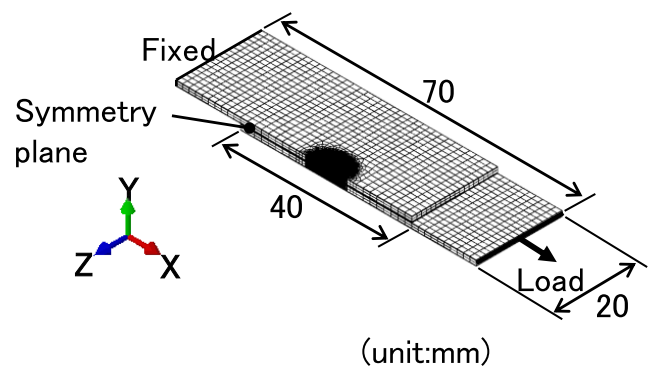

(a) Boundary conditions
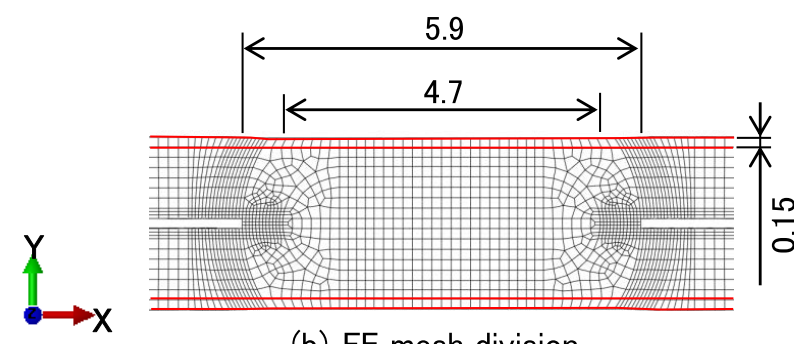

(b) FE mesh division.

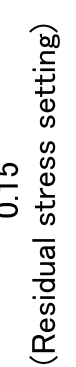

(b) Mesh division

Fig. 12. Finite element model of the spot welded joints. (Online version in color.)
2 are the respective cases where those without and with shot blasting are assumed. In both Case 1 and Case 2, the residual stress caused by spot welding was not established in order to simplify the analysis model. In Case 2, compressive residual stress of $500 \mathrm{MPa}$ that was caused by the shot blasting was applied over the entire superficial layer except for the overlapped surface in the directions of $\sigma_{x}$ and $\sigma_{z}$. Young's modulus and Poisson's ratio of 205.9 GPa and 0.3, respectively, were set as the material property values. For the loading condition, the fatigue test load (the maximum load of $1.94 \mathrm{kN}$ during the fatigue test for $\Delta \mathrm{P}=1.75 \mathrm{kN}$ and $\mathrm{R}=0.1$ ) was reproduced by providing an enforced displacement of $0.05 \mathrm{~mm}$ at the end of the steel plates. An elastic analysis was performed, since it was confirmed that no plastic deformation occurred under this load condition.

Figure 14 shows the analysis results of Cases 1 and 2 in which $980 \mathrm{MPa}$ grade steel sheets without and with shot blasting were assumed, respectively. (a), (b), and (c) are the contour figures of the maximum principal stress, the vector distribution map of the maximum principal stress,
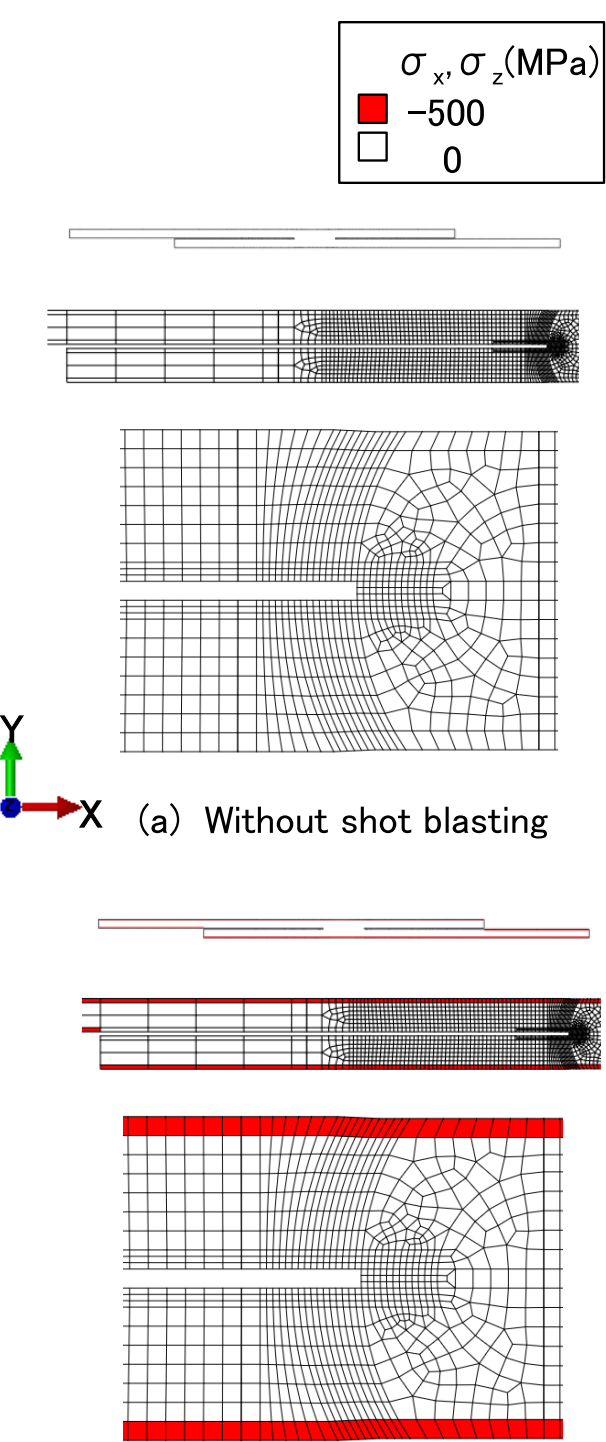

(b) With shot blasting

Fig. 13. Initial residual stress used for the finite element model of $980 \mathrm{MPa}$ steel spot welds. (Online version in color.) 
and the deformation state diagram (deformation magnification: 2 times), respectively. A comparison between the (a) $\mathrm{s}$ in Cases 1 and 2 allowed us to interpret that the region where the maximum principal stress is high is narrower in those with shot blasting. The maximum principal stress in the vicinity of the notch tip of the corona bond portion indicated by the arrow in the figure was approximately 1150 $\mathrm{MPa}$ and $790 \mathrm{MPa}$ in those without and with shot blasting, respectively. This means that the stress at the notch tip of the overlapped surface can be reduced by approximately $360 \mathrm{MPa}$ by applying compressive residual stress on the outer surface. This maximum principal stress might be a driving force that permits cracks to propagate because the red arrows in the figure of Cases 1 and 2 are the highest position that approximately faces toward the vertical direction in the direction along which the fatigue cracks propagated, as shown in Fig. 10. The difference in the maximum principal stress is assumed to be caused by the different deformation modes of the joints at the time of load charging. The deformed state of the specimens is shown in the (c)s of Cases 1 and 2. It emerged that when a spot welded joint is charged with a load, as in Case 1, it deformed in the direction along which the tip of the sheet separation in the overlapped surface opened.

However, when compressive residual stress was conferred on the outer surface before a load was charged, the deformation mode of the joint changed toward the direction along which the opening is inhibited at the tip of the sheet

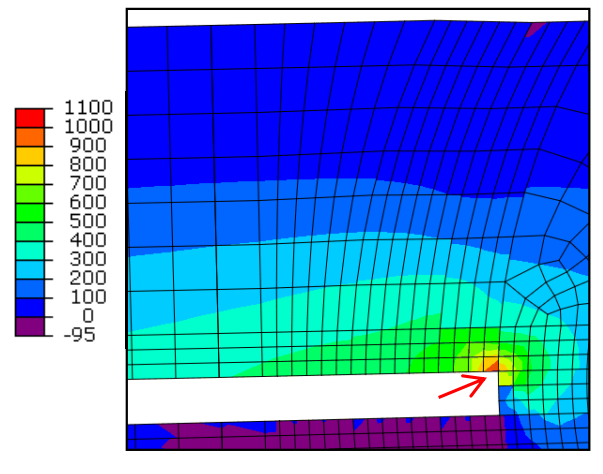

(a) Distribution of maximum principal stress

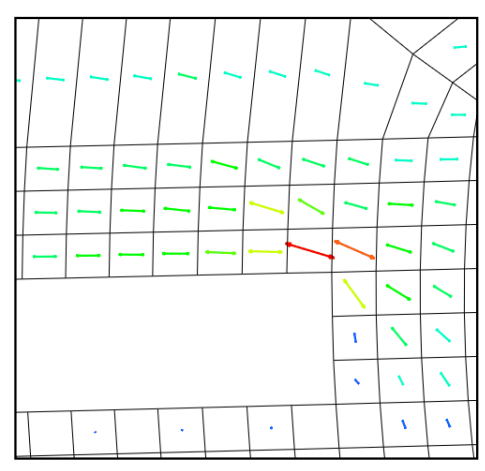

(b) Vector of maximum principal stress

Deformation rate $\mathrm{X} 2$

Load: $1.94 \mathrm{kN}$

(c) Deformation of Joints

Case 1 (Without shot blasting)

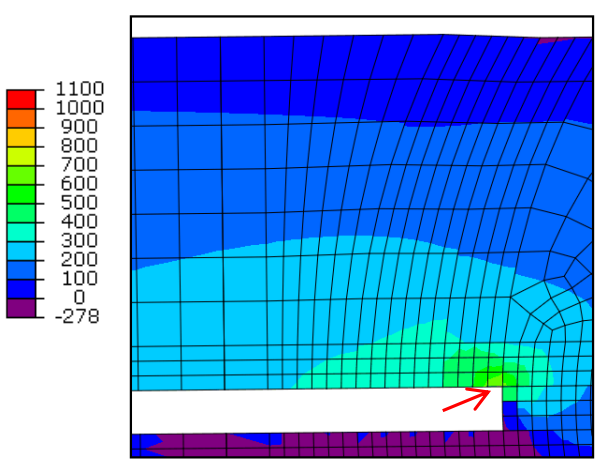

(a) Distribution of maximum principal stress

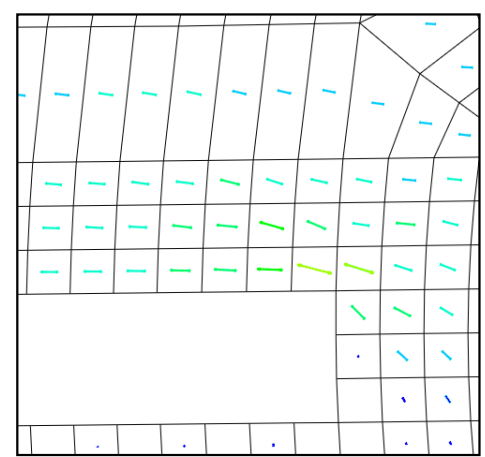

(b) Vector of maximum principal stress

Deformation rate $\mathrm{X} 2$

Load: $1.94 \mathrm{kN}$

(c) Deformation of Joints

Case 2 (With shot blasting)

Fig. 14. Analysis results of spot welds with and without shot blasting. (Online version in color.) 
separation in the overlapped surface, as shown in Case 2. It is assumed that the maximum principal stress at the notch tip of the corona bond portion decreased due to the fact that opening was alleviated at the tip of the sheet separation.

It is assumed that the maximum principal stress decreased by the action of the compressive residual stress on the outer surface due to shot blasting, hence, such a phenomenon occurred whereby the initiation and propagation of fatigue cracks in the overlapped position were delayed.

\section{Conclusions}

This study demonstrated that shot blast processing can improve the fatigue life of spot welded joints using high strength steel sheets with a tensile grade strength of 980 $\mathrm{MPa}$. The mechanism by which the fatigue properties are improved from the standpoint of residual stress and deformation was also considered. The obtained results are as follows:

(1) Shot blast processing after spot welding improved the fatigue strength of the spot welded joints.

(2) While high compressive residual stress was conferred on the outer surface of the shot blasted steel sheets, there was little variation in the residual stress on the side of the overlapped surface.

(3) Shot blasting on the outer surface of the steel sheets delayed both the initiation of the fatigue cracks, which occurred from the notch tip of the corona bond lying around the nugget of the non-shot blasted overlapped face, and their propagation toward the outer surface.

(4) The crack initiation and propagation were delayed in the region where compressive residual stress is not conferred by the shot blasting.

(5) The delay in the initiation and propagation of fatigue cracks caused by shot blasting on the outer surface of steel sheets is considered to be due to the reduction in the maximum principal stress around the corona bond portion because the compressive residual stress that was conferred on the outer surface of the steel sheets inhibited the opening at the tip of the sheet separation of the overlapped surface.

\section{Acknowledgement}

We are grateful to Mr. T. Imamura (Nippon Steel \& Sumitomo Metal Corporation) for his experimental assistance.

\section{REFERENCES}

1) R. Iyengar, M. Amaya, J. Bonnen, K. Citrin, H. T. Kang, S. Laxman, A. Khosrovaneh, N. Schillaci and H. S. Shih: Great Design in Steel, American Iron \& Steel Institute, MI, (2008).

2) E. Nakayama, O. Kazuo, M. Miyahara, M. Yoshida, K. Fukui and H. Fujimoto: SAE Technical Paper 2003-01-2830, SAE, Detroit, (2003).

3) H. Fujimoto and T. Okada: Weld. Technol., 59 (2011), 48.

4) M. Ono, M. Nagae, M. Kabasawa and J. Tanaka: Tetsu-to-Hagané, 70 (1984), S585.

5) Japanese Society of Steel Construction: Fatigue Design Recommendations for Steel Structures, Revised in 2012, Gihodo Shuppan, Tokyo, (2012), 27.

6) A. Ohta, O Watanabe, K. Matsuoka, C. Shiga, S. Nishijima, Y Maeda, N. Suzuki and T. Kubo: Weld. World, 43 (1999), 38.

7) T. Mori, H. Shimanuki and M. Tanaka: Weld. World, 56 (2012), 141.

8) M. Shinozaki, K. Toshiyuki, T. Irie and I. Takahashi: Tetsu-toHagané, 68 (1982), 1444.

9) S. Aoyama and M. Fujimoto: J. Soc. Mater. Sci., Jpn., 20 (1971), 1094.

10) H. Fujimoto, M. Yasuyama, H. Ueda, R. Ueji and H. Fujii: Q. J. Jpn. Weld. Soc., 33 (2015), 144 